ISSN 0258-7122

Bangladesh J. Agril. Res. 36(1) : 97-102, March 2011

\title{
STABILITY STUDY FOR GROWTH DURATION AND GRAIN YIELD OF EXOTIC HYBRID RICE GENOTYPES IN BANGLADESH
}

\author{
P. L. BISWAS ${ }^{1}$, H. N. BARMAN ${ }^{2}$, S. GHOSAL ${ }^{3}$ \\ S. TOHIDUZZAAN ${ }^{4}$ AND M. HAZRAT ALI ${ }^{5}$
}

\begin{abstract}
Twenty eight rice genotypes were evaluated for their stability in respect of grain yield and growth duration during boro season of 2007-08 over five locations viz. Gazipur, Jamalpur, Comilla, Jinaidhah, and Rajshahi. Variances for genotypes, locations, and $G \times E$ interactions were significant for both the traits. Linear components of $\mathrm{G} \times \mathrm{E}$ interactions were insignificant but non- linear components (pooled deviation) were significant. Considering stability parameters $\left(b_{i}\right.$ and $S^{2}$ $\mathrm{d}_{\mathrm{i}}$ ) for days to maturity, genotypes Raja, Ropa-1, and Sera were least responsive to environment $\left(b_{i}=1\right)$ and minimum deviation from regression $\left(S^{2} d_{i}=0\right)$ were stable over the locations. The estimates of stability parameters for grain yield revealed that the genotypes Ropa-1, SL-8, Lily and Sera were higher grain yielder, b value were close to the unity and $S^{2} d_{i}$ value were near to the zero. So, these four genotypes could be considered as the most stable over the environments. Considering both growth duration and grain yield based on stability parameters, the genotypes Ropa and Sera were identified as most stable and could be recommended for release as varieties.
\end{abstract}

Key words: Hybrid rice, stability and exotic.

\section{Introduction}

Stable performance is one of the most desirable properties of a genotype to be released as a variety for wide cultivation. The stability in yield of a variety is greatly influenced by its genetic structure and environmental differences. The environmental fluctuations greatly influence the phenotypic expression of the genotypes in varying degrees and thus exhibit variability in adaptation across locations. Thus the genotype-environment interaction is of major concern to a plant breeder, because such interactions confine the selection of superior cultivars by altering their relative productiveness in different environments (Eaggles and Frey, 1977). So, proper evaluation of promising genotypes over a wide range of environments is very important before releasing varieties. The present investigation was, therefore, undertaken to characterize the stability of 28 hybrid rice genotypes in respect of grain yield and growth duration and to identify the stable ones.

${ }^{1}$ Senior Scientific Officer, Hybrid Rice Project, Bangladesh Rice Research Institute (BRRI), ${ }^{2}$ Scientific Officer, Plant Physiology Division, BRRI, ${ }^{3}$ Scientific Officer, Plant Breeding Division, BRRI, Gazipur 1701, ${ }^{4}$ Senior Marketing Officer, Auto Crop Care Ltd, ${ }^{5}$ Principal Scientific Officer, Rice Farming System Division, BRRI, Gazipur 1701, Bangladesh. 


\section{Materials and Method}

Twenty-six exotic hybrid rice varieties along with two Bangladeshi varieties (BRRI dhan 28 and BRRI dhan 29) as checks were studied in the National Hybrid Rice Trial (NHRT) at five locations viz. Bangladesh Rice Research Institute (BRRI), Gazipur, RARS at Jamalpur, BRRI regional station at Comilla, BADC farm at Pathila (Jinaidha), and BRRI regional station at Rajshahi during Boro season of 2007-08. Seed Certification Agency (SCA) supplied seed materials from four different sources viz, check varieties from BRRI, SL-8 from the Philippines, Arize Dhani from India and rest twenty four varieties from China.The design of experiment was randomized complete block (RCB) with three replications. The plot size was $30 \mathrm{~m}^{2}$. Thirty-day old seedlings were transplanted at $20 \mathrm{~cm} \mathrm{x15} \mathrm{cm} \mathrm{spacing} \mathrm{at} \mathrm{all} \mathrm{the} \mathrm{locations.} \mathrm{Fertilizers} \mathrm{were} \mathrm{applied}$ @ 270:130:120:70:12 kg/ha Urea, TSP, MP, Gypsum, and $\mathrm{ZnSO}_{4}$. TSP, Gypsum, and $\mathrm{ZnSO}_{4}$ were applied as basal at final land preparation. Urea was applied in four splits as basal, 15, 35 DAT and at the time of heading. Two thirds of MP were used at final land preparation and one third at 35 DAT. Standard cultural practices were followed in all the trials to raise the crop successfully. Data on grain yield was taken on whole plot basis and converted into ton per hectare. Growth duration was counted as number of days required to physiological maturity from sowing. The data were analyzed location-wise and then combined over locations. Stability parameters $\left(b_{i}\right.$ and $\left.S^{2} d_{1}\right)$ were estimated according to Eberhart and Russell (1966).

\section{Results and Discussion}

Results of combined analysis of variance for growth duration and grain yield showed high genetic variability among the genotypes (Table 1). Highly significant mean squares due to environment in the present study indicated differences among the environments and their considerable influences on both growth duration and grain yield. Similarly, Haque et al. (1991) reported significant mean squares due to genotypes and environments in rice.

Table 1. Mean sum of squares for analysis of variance for growth duration and grain yield of the tested hybrid rice genotypes.

\begin{tabular}{l|cccc}
\hline \multirow{2}{*}{ Sources of variations } & \multirow{2}{*}{ DF } & \multicolumn{2}{c}{ Mean sum of squares } \\
\cline { 3 - 4 } & & Growth duration & Grain yield \\
\hline Genotype & 27 & $99.376^{* *}$ & $1.460^{* *}$ \\
Environment & 4 & $163.721^{* *}$ & $27.135^{* *}$ \\
Genotyp $\times$ Env. & 108 & $17.564^{* *}$ & $0.878^{* *}$ \\
Env. (Linear) & 1 & $654.884^{* *}$ & $108.542^{* *}$ \\
Genotype x Env. (Linear) & 27 & 10.103 & 0.414 \\
Pooled deviation & 84 & $10.520^{* *}$ & $0.539^{* *}$ \\
Pooled error & 270 & 0.470 & 0.311 \\
\hline
\end{tabular}

* and ** Significant at $5 \%$ and $1 \%$ probability level, respectively. 
Table 2. Location-wise mean growth duration (days) and estimated stability parameters of the tested hybrid rice genotypes.

\begin{tabular}{|c|c|c|c|c|c|c|c|c|c|}
\hline \multirow{2}{*}{ Genotypes } & \multirow{2}{*}{ Source } & \multicolumn{5}{|c|}{ growth duration (days) over location } & \multirow{2}{*}{ Mean } & \multirow{2}{*}{$b_{i}$} & \multirow{2}{*}{$\mathrm{S}^{2} \mathrm{~d}_{\mathrm{i}}$} \\
\hline & & Gazipur & Jamalpur & Comilla & Jenaidah & Rajshahi & & & \\
\hline Raja & China & 142.67 & 147.67 & 143.67 & 142.00 & 147.00 & 144.60 & 1.02 & 0.24 \\
\hline TK-2 & China & 149.00 & 157.00 & 151.33 & 149.00 & 149.67 & 151.20 & 1.10 & $5.38 * *$ \\
\hline Ropa-1 & China & 150.00 & 150.33 & 149.33 & 148.00 & 149.33 & 149.40 & 0.28 & 0.02 \\
\hline $\begin{array}{l}\text { BRRI } \\
\text { dhan } 28\end{array}$ & $\begin{array}{l}\text { BRRI } \\
\text { (Ck) }\end{array}$ & 145.00 & 145.33 & 141.00 & 139.33 & 143.67 & 142.87 & 0.78 & $3.91 * *$ \\
\hline Agro-G-2 & China & 147.33 & 155.00 & 150.67 & 141.67 & 152.00 & 149.33 & 2.04 & I. $81 * *$ \\
\hline Panna-l & China & 149.00 & 150.00 & 150.00 & 149.33 & 152.00 & 150.07 & 0.26 & $0.80^{*}$ \\
\hline TK-7 & China & 146.67 & 151.00 & 145.00 & 141.67 & 148.33 & 146.53 & 1.38 & $1.04^{*}$ \\
\hline BRRIdhan29 & BRRI (Ck) & 152.00 & 159.00 & 155.00 & 156.33 & 160.67 & 156.60 & 0.87 & $9.04 * *$ \\
\hline SL-8 & Philippines & 147.33 & 144.33 & 149.00 & 141.67 & 148.33 & 146.13 & 0.38 & $10.96^{* *}$ \\
\hline Sampod & China & 149.00 & 150.33 & 145.33 & 145.00 & 160.00 & 151.73 & 1.31 & $29.43^{* *}$ \\
\hline Bejoy-5 & China & 140.33 & 142.00 & 133.33 & 138.33 & 137.67 & 138.33 & 0.43 & $12.36^{* *}$ \\
\hline Jumuna & China & 144.00 & 150.00 & 145.00 & 149.00 & 150.00 & 147.60 & 0.51 & $8.59 * *$ \\
\hline Arize Dhani & India & 149.67 & 163.33 & 168.67 & 168.67 & 161.67 & 162.40 & -0.21 & $79.89 * *$ \\
\hline Lily-1 & China & 145.67 & 151.00 & 145.00 & 145.00 & 147.33 & 146.80 & 0.93 & $1.38 * *$ \\
\hline Sera & China & 146.33 & 150.00 & 147.00 & 145.00 & 148.00 & 147.27 & 0.77 & -0.39 \\
\hline Heera-3 & China & 146.00 & 151.00 & 144.67 & 145.33 & 149.67 & 147.33 & 1.02 & $2.08 * *$ \\
\hline WBR-2 & China & 146.00 & 156.33 & 149.00 & 142.00 & 151.00 & 148.87 & 2.20 & 0.25 \\
\hline Heera-6 & China & .150 .33 & 150.00 & 151.00 & 144.67 & 150.00 & 149.20 & 0.68 & $4.74^{* *}$ \\
\hline Chamak-1 & China & 149.33 & 155.67 & 143.00 & 138.00 & 152.00 & 147.60 & $2.63^{*}$ & $12.60 * *$ \\
\hline TK-1 & China & 149.67 & 156.67 & 150.33 & 156.00 & 153.00 & 153.13 & 0.31 & $12.32 * *$ \\
\hline HG-101 & China & 150.00 & 158.33 & 151.67 & 157.67 & 159.67 & 155.47 & 0.69 & $20.87^{* *}$ \\
\hline Heera-5 & China & 152.67 & 154.33 & 149.00 & 145.33 & 151.67 & 150.60 & 1.20 & $4.94 * *$ \\
\hline Rajkumar & China & 148.67 & 150.00 & 142.67 & 142.00 & 148.00 & 146.27 & 1.12 & $7.77 * *$ \\
\hline L.P.-106 & China & 151.33 & 152.67 & 149.00 & 151.67 & 151.33 & 151.20 & 0.17 & $1.71^{* *}$ \\
\hline $\begin{array}{l}\text { Ropushi } \\
\text { Bangla- I }\end{array}$ & China & 150.67 & 155.00 & 150.67 & 142.33 & 150.00 & 149.73 & 1.66 & $6.21 * *$ \\
\hline WBR-5 & China & 149.00 & 155.00 & 157.33 & 142.00 & 149.67 & 150.60 & 1.67 & $25.26 * *$ \\
\hline L.P-5 & China & 152.33 & 156.00 & 157.00 & 144.67 & 152.33 & 152.47 & 1.45 & $14.45^{* *}$ \\
\hline Taj-1 & China & 151.00 & 155.67 & 150.33 & 145.00 & 150.00 & 150.40 & 1.38 & $3.78 * *$ \\
\hline Env.Mean & & 148.25 & 152.61 & 149.07 & 146.31 & 150.86 & 149.42 & & \\
\hline Env.Index & & -1.17 & 3.19 & -0.35 & -3.11 & 1.44 & & & \\
\hline
\end{tabular}

* and ** indicate significant at $5 \%$ and $1 \%$ probability level, respectively. 
The genotype $\mathrm{x}$ environment interactions were highly significant for growth duration and grain yield, which indicated significant differences among the regression coefficients and that might be extended for stability analysis. The linear component of $\mathrm{G} \times \mathrm{E}$ interaction was insignificant for growth duration and grain yield, but non-linear component (pooled deviation) was significant for both the traits, which indicated that the genotypes differed considerably in respect of their stability. Hoque et al. (2001) found insignificant linear and significant nonlinear component of the interaction in rice for grain yield.

The stability parameters i.e., regression coefficient $\left(b_{1}\right)$ and deviation from regression $\left(\mathrm{S}^{2} \mathrm{~d}_{\mathrm{i}}\right)$ for growth duration of individual genotypes are presented in Table 2. Genotypes having less growth duration, regression coefficient $\left(\mathrm{b}_{1}\right)$ near to unity and least deviation from regression $\left(\mathrm{S}^{2} \mathrm{~d}_{\mathrm{i}}\right)$ were considered as suitable. The lowest growth duration was found in Bejoy-5 followed by BRRI dhan 28. Most of the genotypes matured earlier at Gazipur than at Jamalpur followed by that of Rajshahi. Both insignificant linear and non- linear components showed by the genotypes Raja, Ropa-1, and Sera indicated non-existence of genotypesenvironment interaction for growth duration. The genotypes also showed minimum growth duration. So, considering growth duration, these can be recommended as stable genotypes over locations. The genotype Chamak-I showed significant $b_{1}$ and $S^{2} d_{1}$ suggesting that linear and non- linear components are responsible and thus growth duration of the genotype are to be predictable. The rest of the genotypes also showed significant $S^{2} d_{1}$ indicating that the growth duration of those genotypes are not predictable. The average yield of the genotypes under different locations and the mean yield over all locations along with regression co-efficient $\left(b_{1}\right)$ and deviation from regression $\left(S^{2} d_{i}\right)$ are presented in Table 3. The yields of the most of the genotypes varied with the changes of growing environments. The difference in yield among genotypes indicated their differential yielding ability under different environmental conditions.

Most of the genotypes produced higher grain yield at Rajshahi than Jamalpur (Table 3). Positive environmental index also indicated higher yield potentials at these locations. An examination of two stability parameters bi and $S^{2} d_{i}$ showed a significant linear component (regression coefficient) only for one genotype (Agro-G-2), but four genotypes (Sampod, Heera-6, Chamak, and Rajkumar) showed non-linear (deviation from regression) sensitivity (Table 3). Both insignificant linear and non-linear components showed by other genotypes indicated nonexistence of $\mathrm{G} \times \mathrm{E}$ interaction. None of the genotypes showed combined $b$ and $S^{2} d_{i}$ sensitivity suggesting that linear or non-linear component alone was responsible for $\mathrm{G} \times \mathrm{E}$ interaction. These results agreed with the findings of Ray et al. (1991). It is noticeable that none of the genotypes gave negative regression co-efficient value. 
Table 3. Location-wise mean grain yield ( $t / h a)$ and estimated stability parameters of the tested hybrid rice genotypes.

\begin{tabular}{|c|c|c|c|c|c|c|c|c|c|}
\hline \multirow{2}{*}{ Genotypes } & \multirow{2}{*}{ Source } & \multicolumn{5}{|c|}{ Location-wise mean yield (t/ha) } & \multirow{2}{*}{ Mean } & \multirow{2}{*}{$b_{i}$} & \multirow{2}{*}{$\mathrm{S}^{2} \mathrm{~d}_{\mathrm{i}}$} \\
\hline & & Gazipur & Jamalpur & Comilla & Jenaidah & Rajshahi & & & \\
\hline Raja & China & 5.89 & 7.32 & 4.82 & 6.81 & 7.19 & 6.41 & 0.96 & -0.03 \\
\hline TK-2 & China & 6.47 & 7.47 & 4.73 & 7.56 & 7.57 & 6.76 & 1.01 & 0.38 \\
\hline Ropa-1 & China & 6.42 & 7.81 & 6.42 & 7.55 & 9.36 & 7.51 & 1.11 & 0.06 \\
\hline $\begin{array}{l}\text { BRRI } \\
\text { dhan } 28\end{array}$ & BRRI (Ck) & 5.32 & 6.37 & 4.73 & 5.62 & 7.29 & 5.87 & 0.87 & 0.03 \\
\hline Agro-G-2 & China & 6.77 & 7.34 & 7.33 & 7.96 & 7.29 & 7.34 & $0.22 *$ & -0.14 \\
\hline Panna-i & China & 6.53 & 7.87 & 5.67 & 7.84 & 6.54 & 6.89 & 0.61 & 0.41 \\
\hline TK-7 & China & 5.89 & 7.93 & 4.94 & 7.00 & 7.41 & 6.63 & 1.12 & 0.02 \\
\hline $\begin{array}{l}\text { BRRI } \\
\text { dhan } 29\end{array}$ & BRRI (Ck) & 6.08 & 7.07 & 4.53 & 7.25 & 7.66 & 6.52 & 1.08 & 0.27 \\
\hline SL-8 & Philippines & 5.40 & 7.66 & 6.22 & 8.10 & 7.40 & 6.96 & 1.01 & 0.03 \\
\hline Sampod & China & 5.98 & 7.99 & 4.04 & 7.98 & 7.05 & 6.61 & 1.34 & $1.04^{* *}$ \\
\hline Bejoy-5 & China & 4.18 & 6.86 & 4.33 & 6.29 & 5.41 & 5.42 & 1.00 & 0.24 \\
\hline Jumuna & China & 5.17 & 8.57 & 6.33 & 6.84 & 9.27 & 7.23 & 1.56 & 0.27 \\
\hline Arize Dhani & India & 5.97 & 9.24 & 6.33 & 7.07 & 8.23 & 7.37 & 1.22 & 0.23 \\
\hline Lily-i & China & 5.48 & 8.15 & 7.03 & 7.47 & 8.31 & 7.29 & 1.04 & 0.01 \\
\hline Sera & China & 7.09 & 7.71 & 6.43 & 7.16 & 8.95 & 7.47 & 0.75 & 0.15 \\
\hline Heera-3 & China & 5.90 & 7.00 & 6.30 & 6.35 & 8.34 & 6.78 & 0.77 & 0.16 \\
\hline WBR-2 & China & 5.82 & 7.61 & 4.76 & 8.10 & 8.15 & 6.89 & 1.42 & 0.18 \\
\hline Heera-6 & China & 7.41 & 8.18 & 5.01 & 7.10 & 7.92 & 7.12 & 0.83 & $0.89 * *$ \\
\hline Chamak-I & China & 4.05 & 6.19 & 6.80 & 7.40 & 8.19 & 6.53 & 1.10 & i. $41^{* *}$ \\
\hline TK-1 & China & 4.83 & 6.27 & 5.75 & 6.31 & 7.48 & 6.13 & 0.86 & -0.03 \\
\hline HG-101 & China & 4.08 & 7.12 & 5.90 & 6.53 & 7.34 & 6.19 & 1.20 & 0.12 \\
\hline Heera-5 & China & 4.51 & 7.36 & 4.73 & 7.73 & 7.03 & 6.27 & 1.45 & 0.10 \\
\hline Rajkumar & China & 5.26 & 7.60 & 7.63 & 6.64 & 6.51 & 6.73 & 0.32 & $0.82 *$ \\
\hline L.P.-106 & China & 5.25 & 6.94 & 6.82 & 6.50 & 7.80 & 6.66 & 0.70 & 0.20 \\
\hline $\begin{array}{l}\text { Ropushi } \\
\text { Bangla-1 }\end{array}$ & China & 5.41 & 7.13 & 6.66 & 6.83 & 7.38 & 6.68 & 0.66 & -0.10 \\
\hline WBR-5 & China & 4.88 & 6.95 & 5.29 & 6.81 & 7.09 & 6.20 & 1.04 & -0.29 \\
\hline L.P-5 & China & 3.68 & 6.13 & 4.56 & 6.17 & 7.66 & 5.64 & 1.49 & 0.00 \\
\hline Taj-1 & China & 4.34 & 7.62 & 5.46 & 6.35 & 7.27 & 6.21 & 1.29 & -0.07 \\
\hline Env.Mean & & 5.50 & 7.41 & 5.70 & 7.05 & 7.61 & 6.65 & & \\
\hline Env.Index & & -1.25 & 0.66 & -0.96 & 0.39 & 0.96 & & & \\
\hline
\end{tabular}

*and ** indicate significant at 5\% and 1\% probability level, respectively. 
The genotypes Ropa-1, SL-8, Lily-I and Sera showed higher grain yield, b value close to unity and $S^{2} d_{i}$ value near to zero (Table 3 ). So, these genotypes were considered as the most stable with the changes of environments and possessed better adaptability over wider range of environments. Two lines viz. Agro-G-2 and Heera-6 showed higher grain yield but significant $b_{i}$ and $S^{2} d_{i}$ values, respectively, indicating that these two genotypes could be recommended only for favourable environment. Similar genotypes have also been reported by Abassi et al. (1991) in rice. The genotypes Raja, BRRI dhan 28, Heera-3, and Ropushi exhibited grain yield close to grand mean, less than unity $b_{i}$ value and very low $S^{2} d_{i}$ estimates. For these reasons, the genotypes were least sensitive to environmental conditions and might be specially advocated for unfavourable environments where it would give average yield performance. Reddy (1991) also reported similar results in rice. Considering both growth duration and grain yield (based on stability parameters), the genotypes Ropa and Sera were identified as most stable and could be recommended for release as new varieties.

\section{References}

Abassi, F. M., M. A. Sager and A. Rabbani. 1991. Stability for yield of medium-long grain rice varieties and advanced lines. International Rice Research News Letter. 16:1-9.

Eaggles, H. A. and K. J. Frey. 1977. Repeatability of the stability variance parameter in oats. Crop Sci. 17: 253-256

Eberhart, S.A. and W. A.Russell. 1966. Stability parameters for comparing varieties. Crop Sci. 6: 36-40.

Haque, Q.A., N. M. Miah, M. A. Kabir, P.K.S. Ray, M. U. Ghani, M. L. All and M. S. Islam, 1991. Yield stability of some rice genotypes (in South Asia). Bangladesh Rice genotypes (in South Asia). Bangladesh Rice J. 2 (1-2):69-74.

Hoque, M. E., M.K. Bashar, M. Khanam, N. Ahmed and M. F. Rabbi. 2001. Genotypeenvironment interaction and stability analysis of some tissue culture derived rice genotypes. J. Agric. Sci. Tech. 2:1-4

Ray, P. K.S., N. M. Miah, M. S. J. Mamin and M. G.Mostafa, 1991. Evaluation of some promising rice genotypes at six locations in Bangladesh. Bangladesh J. Pl.Breed. Genet. 4: 1-3

Reddy, J. N. 1991.Genotype and environment interaction in short-duration rice (Oryza sativa L). Indian J. Agric. Sci. 61(5): 320-321 